\title{
Analisa dimensi pori sponge sebagai pelat penyerap terhadap kinerja solar still double slope tipe $\mathrm{v}$
}

\author{
Habib Indradaya $^{1^{*}}$, Nova R. Ismail ${ }^{2}$, Akhmad Farid ${ }^{3}$ \\ Teknik Mesin, Fakultas Teknik, Universitas Widyagama Malang ${ }^{1.2 .3}$ \\ Jalan borobudur No 35, Malang, Indonesia \\ Email: indragoklik@gmail.com ${ }^{1}$, novarislampung@yahoo.co.id ${ }^{2}$, af_arid@yahoo.com ${ }^{3}$
}

\begin{abstract}
There have been many studies for the development of solar distillation to increase its efficiency and economic benefit, component design improvement of the solar still is one of the directions to increase its productivity. To facilitate desalinate-water evaporation a thin stream. Thin stream water flow is needed, which can be obtained by flowing feed water through the pores in a capillary manner. Therefore, research on the effect of sponge pore dimensions on the performance of solar still double slope type $V$ is performed. This research was carried out experimentally to compare the pore dimensions of sponges with the performance of solar still double slope type $V$. The results of this study indicate that the best solar still double slope type $V$ is using $0.089 \mathrm{~mm}$ sponge dimensions, with an obtained capillary flow rate of sponge at $0.0000043 \mathrm{~m} / \mathrm{s}$ in average efficiency of $37.311 \%$, and the yield of condensate water per day is 3,447 liters $/ \mathrm{m}^{2}$.
\end{abstract}

Keywords: Pore dimension, sponge absorbent plate, solar still.

\begin{abstract}
Abstrak
Telah banyak penelitian untuk pengembangan solar distilation agar lebih efisien dan ekonomis, dari perubahan desain hingga komponen untuk meningkatkan kinerja dari solar distillation. Untuk memudahkan evaporasi di perlukan air umpan dalam bentuk aliran yang tipis. Aliran air yang tipis dapat di peroleh dengan mengalirkan air umpan melalui pori-pori secara kapiler. Dengan demikian di perlukan penelitian tentang pengaruh dimensi pori sponge terhadap kinerja solar still double slope tipe V. Penelitian ini dilakukan secara eksperimen, untuk membandingkan dimensi pori sponge terhadap kinerja solar still double slope tipe $\mathrm{V}$. Hasil dari penelitian ini menunjukan bahwa solar still double slope tipe $\mathrm{V}$ menggunakan dimensi pori sponge $0.089 \mathrm{~mm}$, didapat laju aliran air kapiler pada sponge $0,0000043 \mathrm{~m} / \mathrm{s}$ dengan effisiensi rata-rata yaitu sebesar $37,311 \%$, dan hasil air kondensat perharinya sebesar 3,447 liter $/ \mathrm{m}^{2}$.
\end{abstract}

Kata kunci: Dimensi pori, pelat penyerap sponge, solar still.

\section{Pendahuluan}

Air bersih begitu penting untuk kelangsungan hidup umat manusia, manfaat air bersih sangat besar bagi tubuh kita, negara Indonesia dengan perairan yang luas dan wilayah pesisir begitu banyak, sumber air tidak terbatas adalah air laut, namun kualitas dari air laut sangatlah buruk karena kandungan garam atau TDS (Total Dissolved Solid) yang sangat tinggi [1]. Salah satu caranya adalah dengan penerapan teknologi pengolahan air laut yang disebut proses desalinasi [2], proses deslinasi yang ramah lingkungan adalah dengan tenaga matahari [3].

Melakukan kombinasi kubus sponge pada basin, penggunaan kubus batu bara pada basin mehasilkan peningkatan produksi yang signifikan, yaitu hingga $273 \%$. Kubus sponge menambah luas permukaan untuk mempercepat terjadinya penguapan, kombinasi optimal yaitu: sponge kubus dengan sisi $6 \mathrm{~cm}$, rasio 
volume air sponge ke basin $20 \%$ dan kedalaman air $7 \mathrm{~cm}$. kubus sponge lebih efektif daripada kubus yang terbuat dari batu bara atau baja hitam [4].

Dari penelitian yang dilakukan menghasilkan pelat penyerap menggunakan pasir besi tanpa campuran dan pasir lumajang memiliki temperatur dan efisiensi lebih tinggi, dan pelat penyerap radiasi matahari menggunakan pasir besi tanpa kotoran (jumlah pasir besi 100\%) temperatur dan efisiensinya lebih tinggi [4].

Dalam penelitian ini, menyajikan desain, fabrikasi dan pengujian solar still double slope dengan eksternal parabola internal dan reflektor parabola dan juga optimasi sudut kemiringan reflektor datar eksternal untuk kondisi iklim Mesir. Reflektor datar eksternal miring pada (30 , $45^{\circ}, 60^{\circ}$ dan $75^{\circ}$ ) pada bidang horizontal. Kedalaman air di dalam basin $1 \mathrm{~cm}$. Hasil eksperimen dibandingkan dengan solar still double slope konvensional. Sudut kemiringan optimal adalah $60^{\circ}$ dengan produktifitas harian maksimum $9,89 \mathrm{lit} / \mathrm{m}^{2}$ [5].

Penelitian ini bertujuan untuk menyelidiki sifat-sifat pengangkutan kapiler dari beton dan batu alam yang akan digunakan sebagai bahan pelat penyerap peralatan solar still. Foto skala makro dan uji porositas telah dilakukan untuk menentukan karakteristik media berpori. Hasil yang diambil dari foto skala makro menunjukkan bahwa peningkatan ukuran lubang pori dengan ukuran partikel agregat yang lebih besar di kedua jenis agregat. Porositas tertinggi ditemukan pada beton dengan pasir besi dengan ukuran agregat $0,250 \mathrm{~mm}$ spesimen dengan nilai $57,77 \%$. Porositas tertinggi diperoleh pada beton dengan pasir Lumajang dengan ukuran agregat $0,250 \mathrm{~mm}$ spesimen dengan jumlah $0,224 \%$. Volume terbesar diserap air laut dan koefisien serapan juga diperoleh dalam beton dengan pasir Lumajang dengan ukuran agregat 0,250 dengan nilai $8,05 \mathrm{ml}$. dan 9,58 x10-5 $\mathrm{m} / \mathrm{s} 0.5$ masing-masing. Namun beton dengan pasir besi dengan ukuran agregat 0,250 memiliki laju aliran massa tertinggi dengan nilai 3,25 x10-7 $\mathrm{kg} / \mathrm{s}$. Interkonektivitas antara saluran juga memiliki peran penting dalam nilai laju aliran massa yang terjadi pada spesimen batu alam [6]. Laju perpindahan panas terbesar diperoleh pada beton dengan pasir besi $0,125 \mathrm{~mm}$ dengan nilai $0,256 \mathrm{~W}, 0,402$ $\mathrm{W}$, dan $0,524 \mathrm{~W}$ pada setiap penambahan daya. Laju nilai transfer massa sama dengan laju penguapan yang terjadi dan sangat bergantung pada kekuatan kapiler dari masing-masing spesimen [7].

Dari hasil penelitian diatas, maka perlu dilakukannya pengembangan penelitian mengenai dimensi pori pada sponge sebagai pelat penyerap pada solar still. Untuk meningkatan kinerja solar still dapat dilakukan dengan menggunakan bahan dasar sponge yang memiliki poripori. Air yang mengalir melalui pori-pori terjadi secara kapiler dari permukaan bawah menuju permukaan atas pelat penyerap dalam bentuk lapisan tipis, dan dengan adanya panas, maka akan terjadi peroses evaporasi lebih cepat di bandingkan solar still konvensional. Dari penelitian sebelumnya menggunakan kaca penutup double slope dapat meningkatkan kinerja solar still dibandingkan single slope. Dengan demikian, perlu dilakukan penelitian tentang pengaruh dimensi pori sponge sebagai pelat penyerap terhadap kinerja solar still double slope tipe V. Tujuan Penelitian adalah Untuk mengetahui laju aliran air dan pengaruh dimensi pori sponge sebagai penyerap terhadap kinerja solar still double slope tipe V.

\section{Metode Penelitian}

Penelitian ini menggunakan variabel bebas dimensi pori sponge, $0.089 \mathrm{~mm}, 0.123$ $\mathrm{mm}$ dan $0.216 \mathrm{~mm}$. Sedangkan variabel terikatnya adalah laju Aliran, Temperatur kaca penutup ( $\mathrm{Tg}$ ), temperatur pelat penyerap (Tp), temperatur lingkungan ( $\mathrm{Tl}$ ), Temperatur air (Ta), produktifitas air kondensat $\left(\mathrm{m}_{\mathrm{p}}\right)$ dan radiasi total matahari (Gt).

Efisiensi alat destilasi adalah perbandingan energi panas dalam proses 
penguapan air laut hingga menjadi air bersih terhadap besar radiasi yang diterima oleh alat destilasi melalui pelat penyerap radiasi matahari dalam selang waktu tertentu. Untuk perhitungan efisiensi dapat digunakan persamaan berikut [8]:

Keterangan:

$$
\eta_{d}=\frac{m_{k} \times h_{f g}}{A_{c} \cdot I_{t} \cdot t} \times 100 \%
$$

$m_{k}=$ total massa air kondensat $(\mathrm{kg})$

$h_{f g}=$ panas laten penguapan $(\mathrm{kJ} / \mathrm{kg})$

$A_{c}=$ luas pelat penyerap $\left(\mathrm{m}^{2}\right)$

$I_{t}=$ intensitas radiasi matahari $\left(\mathrm{W} / \mathrm{m}^{2}\right)$

$\mathrm{t}$ = lama waktu pengujian (s)

Adapun set up perlatan sebagai berikut:

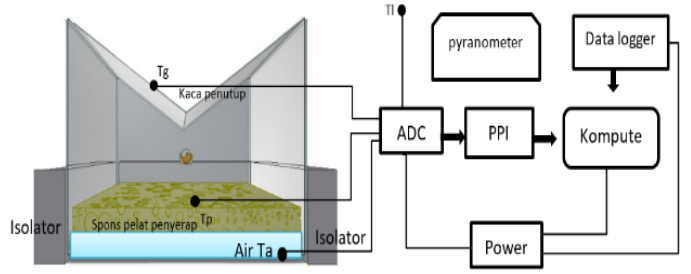

Gambar 1. Set up peralatan uji

\section{Hasil dan Pembahasan}

1. Pengujian dimensi pori

Dari hasil foto, kemudian diolah menggunakan software ImageJ dan hasilnya dapat dilihat pada tabel 1 .

Tabel 1. Rata-rata dimensi pori sponge dari tiga jenis sponge berbeda.

\begin{tabular}{ccc}
\hline $\begin{array}{c}\text { Jenis } \\
\text { Sponge }\end{array}$ & Gambar Pori & $\begin{array}{c}\text { Dimensi } \\
\text { Pori }\end{array}$ \\
\hline S1 & $0,089 \mathrm{~mm}$ \\
\hline S2 & $0,123 \mathrm{~mm}$ \\
\hline S3 & & $0,216 \mathrm{~mm}$ \\
\hline
\end{tabular}

Pada sponge berwarna kuning memiliki ukuran pori-pori yaitu $0,089 \mathrm{~mm}$, pada sponge merah memiliki dimensi poripori $0,123 \mathrm{~mm}$ dan pada sponge putih memiliki dimensi pori-pori $0,216 \mathrm{~mm}$. Pada penerapannya seluruh permukaan spon dicat berwarna hitam doff.

2. Analisa laju aliran air

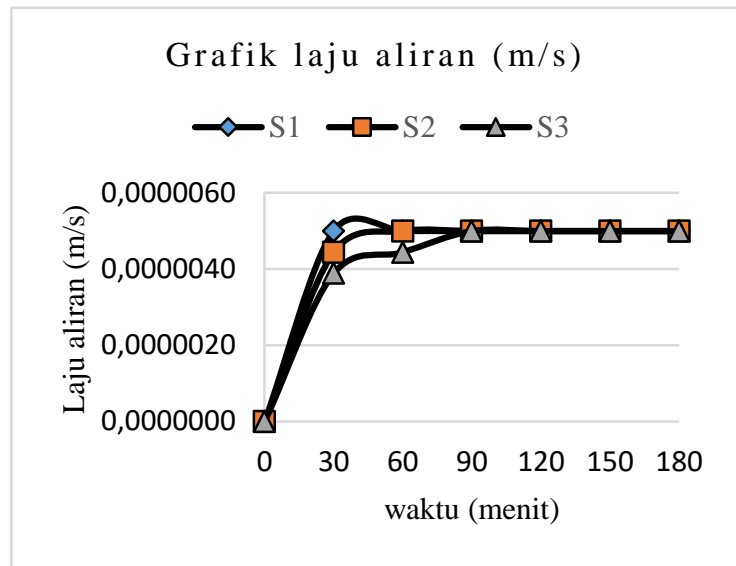

Gambar 2. Laju aliran air laut secara kapiler

Gambar 2 menunjukkan laju alir air tiap 30 menit, dan dari 3 dimensi pori spon yang diuji yaitu; dimensi pori $0,089 \mathrm{~mm}$, $0,123 \mathrm{~mm}$ dan 0,216 $\mathrm{mm}$. Dari hasil pengujian menunjukan sponge dengan dimensi 0,089 $\mathrm{mm}$ menghasilkan laju aliran tertinggi dengan rata-rata sebesar 0,0000042 $\mathrm{m} / \mathrm{s}$, dibandingkan dengan dimensi pori yang lain.

3. Analisa produktifitas dan effisiensi solar still

Dari data temperatur dan produktifitas, kemudian dilakukan perhitungan efisiensi. Adapun hasil produktifitas dan efisiensi dapat dilihat pada Gambar 3, sebagai berikut:

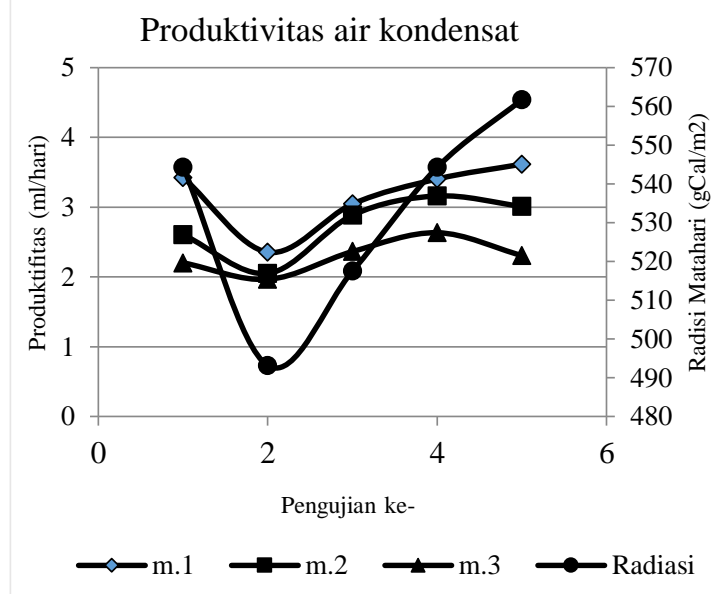

(a) 


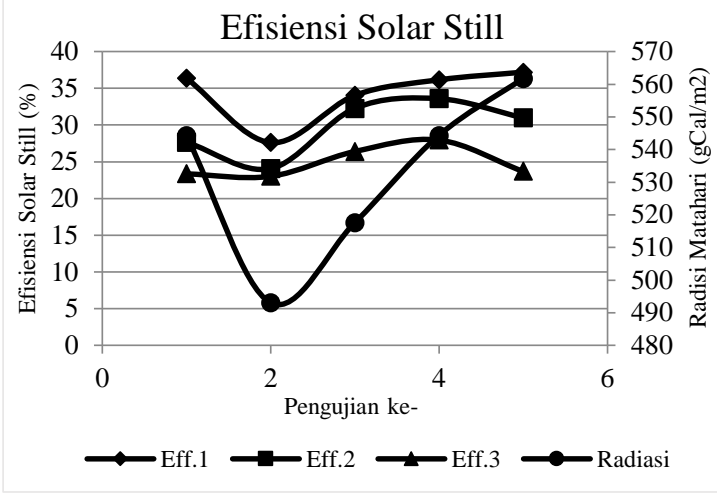

(b)

Gambar 3. (a) grafik produktivitas solar still, (b) grafik efisiensi solar still,

Dari gambar 3 dan 4 menunjukkan grafik produktivitas dan efisiensi solar still double slope tipe V. Dengan rata-rata hasil tertinggi $3,447 \quad 1 / \mathrm{m}^{2} / \mathrm{h}$ dengan effisiensi terbaik $37.311 \%$, dan hasil terendah 2.341 $1 / \mathrm{m}^{2} / \mathrm{h}$ dengan efisiensi $25.409 \%$, hal ini dipengaruhi oleh dimensi pori dan kapilaritas. Dimensi pori akan mempengaruhi pembentukan membuat lapisan tipis air dan kapilaritas akan mempengaruhi kemampuan air naik ke permukaan pelat penyerap. Aliran air laut di dalam pori yang tipis di dalam pelat penyerap dapat mempercepat proses evaporasi. Sehingga dapat meningkatkan produktifitas dan efisiensi solar still.

\section{Pembahasan}

Dari penelitian pelat penyerap sponge terhadap kinerja solar still double slope tipe $\mathrm{V}$ ini sebagai beikut: penelitian pertama mengukur dimensi pori-pori sponge, didapat dimensi pori yaitu: 0,089 $\mathrm{mm}, 0,123 \mathrm{~mm}, 0,216 \mathrm{~mm}$. dimensi pori menghasilkan perbedaan pada laju aliran air yang naik secara kapiler, laju aliran air tertinggi dimiliki oleh dimensi pori 0,089 $\mathrm{mm}$ dengan rata-rata $0,0000042 \mathrm{~m} / \mathrm{s}$, dan terrendah dimensi pori $0,216 \mathrm{~mm}$ yaitu $0,0000033 \mathrm{~m} / \mathrm{s}$.

Dari hasil pengujian dapat membuktikan bahwa semakin kecil dimensi pori-pori pada sebuah sponge dapat meningkatkan kapilaritas pada sponge tersebut, walaupun aliran air tidak mampu mencapai permukaan atas.
Pengujian alat solar still double slope tipe $\mathrm{V}$ dilakukan selama lima hari untuk mendapatkan hasil yang optimal. Dari hasil pengujian diperoleh efisiensi dari masing-masing spesimen yang diuji yaitu: spesimen sponge satu (S1) diperoleh efisiensi sebesar 37,311\%, spesimen sponge dua (S2) sebesar 30,503 \% dan spesimen sponge tiga (S3) sebesar 25,409\%. Perbedan dialami dari setiap spesimen disebabkan oleh berbagai faktor, diantaranya adalah dimensi pori masingmasing sponge dan cuaca.

Hasil akhir dari alat solar still double slope tipe $\mathrm{V}$ ini adalah air kondensat yang dihasilkan setiap harinya. Solar still double slope tipe $\mathrm{V}$ menggunakan pelat sponge satu (S1) menghasilkan air tawar sebesar 3,447 liter $/ \mathrm{m}^{2} /$ hari, pada sponge dua (S2) di dapat 2,820 liter $/ \mathrm{m}^{2} /$ hari dan sponge tiga (S3) mendapatkan 2,341 liter.

\section{Kesimpulan}

Dimensi pori pada sponge dapat menentukan laju aliran air yang naik secara kapiler pada pori sponge dengan semakin kecilnya dimensi pori sponge aliran air semakin cepat, pada pengujian ini dimensi pori terbaik adalah $0,089 \mathrm{~mm}$, didapat laju aliran rata-rata sebesar $0,0000042 \mathrm{~m} / \mathrm{s}$. Produktivitas air kondensat tertingi menggunakan dimensi pori $0,089 \mathrm{~mm}$ sebesar 3,447 liter/ $\mathrm{m}^{2} /$ hari. Efisiensi solar still tertinggi sebesar $37,311 \%$ yang dimiliki oleh spesimen satu dengan dimensi pori $0,089 \mathrm{~mm}$.

\section{Referensi}

[1] Yuan, G., Wang, Z., Li, H., dan Li, X. 2011. Experimental Study of A Solar Desalination System Based on Humidification-Dehumidification Process. Desalination 277 (2011) 9298.

[2] Deng, R., Xie, L., Lin, H., Liu, J., Han, W. 2010. Integration of Thermal Energy and Seawater Desalination. Energy 36 (2010) 4368-4374. 
[3] Yilmaz, Ibrahim Halil dan Soylemez, Mehmet Sait. 2012. Design and Computer Simulation on Multi-Effect Evaporation Seawater Desalination System Using Hybrid Renewable Energy Sources in Turkey. Desalination 291 (2012) 23-40.

[4] Abu-Hijleh, B. and Rababa'h, H. M. (2003) 'Experimental study of a solar still with sponge cubes in basin', Energy Conversion and Management, 44(9), pp. 1411-1418.

[5] Pratama,;Andika, Pradhana, A. B., Ismoyo, B. and R.Ismail; Nova (2013) 'Analisa Pasir Besi Untuk Meningkatkan Efisiensi Pelat Penyerap Panas Radiasi Matahari', 5(2), pp. 5-9.

[5] Habib, M. (2013) 'Effect of External Reflector Angle on Productivity and Performance of Double Slope Solar still with Internal Parabolic Reflector', IOSR Journal of Mechanical and Civil Engineering (IOSR-JMCE), 9(6), pp. 40-54.

[6] Ismail, N. R., Soeparman, S., Widhiyanuriyawan, D., Wijayanti, W. "The influence of pores size and type of aggregate on liquid mass transfer in porous media", Journal of Engineering and Applied Sciences, 13, pp. 71717178, 2018.

[7] Ismail N. R., Soeparman, S., Widhiyanuriyawan, D., Wijayanti, W. "The influence of pores size and type of aggregate on capillary heat and mass transfer in porous", Journal of Applied Engineering Science, 17, pp. 8-17, 2019.

[8] Duffie J.A. dan Beckman W.A. (1980). Solar Engineering Of Thermal Processes. New York: John Willey \& Sons. 